\title{
ERRATUM
}

\section{Control of filamentous fungal cell shape by septins and formins}

\section{Amy S. Gladfelter}

Nature Reviews Microbiology 4, 223-229 (2006), doi: 10.1038/nrmicro 1345

In the above article, the legend to Figure 1 did not match what was shown in the figure. The correct legend is shown below. We wish to apologize to the author, and to readers, for any confusion caused.
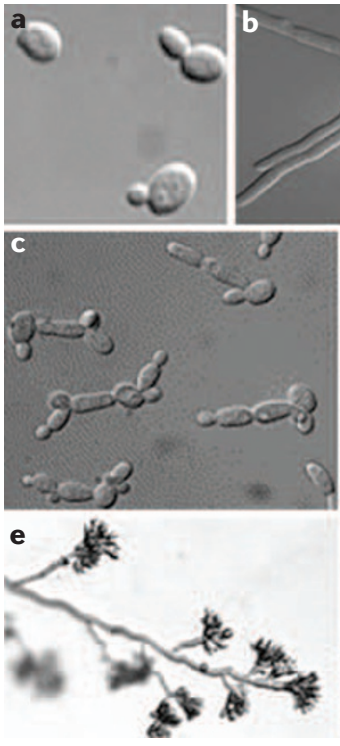
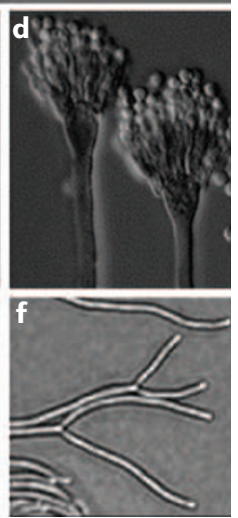

Figure 1 | Examples of diverse fungal cell shapes. a | Budding yeast of Candida albicans. Image reproduced with permission from REF. 23 (C) (2004) The Rockefeller University Press. b | Wild-type branching in Ashbya gossypii. Image kindly provided by Andreas Kaufmann and Peter Philippsen. c| Pseudohyphal cells of C. albicans. Image reproduced with permission from REF. 1 (C) (2004) Elsevier. d | Fruiting bodies in Aspergillus nidulans. Image reproduced with permission from REF. 45 (C) (2004) Elsevier. e | Conditional actin mutants of Neurospora crassa. Image reproduced with permission from REF. 44 (C) (2003) American Society for Cell Biology. $\mathbf{f}$ | Tip-splitting in mature A. gossypii cells. Image reproduced with permission from REF. 46 (C) (2003) American Society for Cell Biology. 